\title{
EMPOWERMENT ISSUES IN JAPAN'S CARE INDUSTRY: NARRATIVES OF FILIPINO NURSES AND CARE WORKERS UNDER THE ECONOMIC PARTNERSHIP AGREEMENT (EPA) LABOUR SCHEME
}

\author{
Ron Bridget T. Vilog* \\ International Studies Department, De La Salle University, \\ 2401 Taft Avenue, Malate, Manila 1004, Philippines \\ E-mail: ron.vilog@dlsu.edu.ph \\ Ma. Keren Happuch D. Arroyo** \\ International Studies Department, De La Salle University, \\ 2401 Taft Avenue, Malate, Manila 1004, Philippines \\ E-mail: ma_keren_arroyo@dlsu.edu.ph \\ Tezla Gael G. Raquinio*** \\ International Studies Department, De La Salle University, \\ 2401 Taft Avenue, Malate, Manila 1004, Philippines \\ E-mail: tezla_raquinio@dlsu.edu.ph
}

Published online: 30 January 2020

To cite this article: Vilog, R. B. T., Arroyo, M K. H. D. and Raquinio, T. G. G. 2020. Empowerment issues in Japan's care industry: Narratives of Filipino nurses and care workers under the Economic Partnership Agreement (EPA) labour scheme. International Journal of Asia Pacific Studies 16 (1): 39-69, https://doi.org/10.21315/ ijaps2020.16.1.2

To link to this article: https://doi.org/10.21315/ijaps2020.16.1.2

\begin{abstract}
Japan has been accepting foreign nurses and care workers through an Economic Partnership Agreement (EPA) with the Philippines, Indonesia and Vietnam. Formore than ten years of its implementation, the EPA framework with the Philippines has confronted tremendous political hurdles from conservative politicians, groups and non-state agents which oppose the free trans-border flow of health workers. The lack of holistic state support has affected the implementation of the labour scheme under the Philippine-Japan Economic Partnership Agreement (PJEPA). In fact, majority of the nurses and care workers have failed the Japanese licensure examination,


and an alarming percentage has decided to return to the Philippines after several years of training. Such trends indicate the failure of PJEPA to achieve a sustainable and mutually benefiting migration project. It is therefore imperative to examine the causes of this failure from the viewpoint of nursing and care delivery discourses. This paper contributes to the emerging literature that investigate EPAs and labour migration, with particular focus on the labour conditions and migrant decisions of individual care providers. Rethinking the concept of empowerment, we argue that the migration management regime, manifested in state's healthcare policies and governance mechanism has been lacking meaningful support and guidance to the healthcare facilities, which translates to workers' structural disempowerment. Nurses and care workers contest their dignity of labour, negotiate their experiences of deskilling, and seek strategies to survive the system. Disempowerment clearly impacts on individual migrant decisions, challenging established mechanisms and threatening the entire migration system to fail.

Keywords: PJEPA, EPA, nurses, care workers, empowerment

\section{INTRODUCTION}

In 2009, Japan started to accept a number of Filipino nurses and care workers through the Philippine-Japan Economic Partnership Agreement (PJEPA). This treaty facilitates the mobility of Filipino health care professionals including registered nurses (RNs) and care workers in order to address the chronic shortage of medical and healthcare staff in Japan. Despite the increasing number of EPA candidates, policy evaluation and reviews for the past ten years of implementation reveal problematic mechanisms of PJEPA from the process of deployment to actual employment. First, it failed to benefit both countries as the number of health workers admitted to the programme were very limited due to the low passing rate of the nursing and care worker licensure examination. Second, the sustainability of the labour scheme has been questioned by policy observers. Many nursing and care worker candidates returned to the Philippines after undergoing rigid training and preparations for the exam for two to three years.

Specific criticisms on the PJEPA centre on the unfair treatment of the candidates who felt that they have become deskilled upon entry to Japan. For instance, both nurses and care workers are considered as trainees until they pass their respective licensure examinations which are written in the Japanese language. Moreover, the nursing curricula in Japan and the Philippines are different in content, scope and training mechanisms (Kawaguchi et al. 2012). In effect, there are noted gaps in terms of the nursing practises and protocols 
that frequently instigate confusion and frustration for both the candidates and the employers. With these criticisms, one can surmise that the PJEPA's loophole is caused by multifaceted and complex problems of the labour scheme. Ogawa (2016: 107) notes that the "intersection of the state, care facilities, and migrant care workers is formulating the globalisation of care that is emerging in Japan," and perhaps the conflicting interests and tensions between these institutions and stakeholders have further deepened the EPA problem. Taking into account the policy revisions and developments of the labour scheme from 2010 to 2018, this paper seeks to investigate the reasons behind the failure of the EPA to establish a sustainable and productive migration path for Filipino nurses and care workers.

The study foregrounds the perspectives of health workers from the Philippines. Recognising the importance of self-perception in theorising empowerment, the paper specifically focuses on the voices of Filipino nurses and care workers who narrate their migrant experiences vis-a-vis their expectations in participating in this migrant venture. Reports from both the Philippine and Japanese governments claim that the PJEPA's provisions have significantly improved in terms of its short-term approaches in providing basic capabilities to the nursing candidates. However, the fundamental problem lies in the migration management framework that fails to support holistic empowerment to the nurses and care workers. In line with this proposition, we argue that policy interventions must be rooted in the structural foundations of Japan's health governance that is designed to empower the care working sector. Moreover, strategic restructuring of the labour scheme is crucial to enhance the career growth and institutional integration of the health workers into the Japanese health system.

Empowerment, in its broad sense, is defined as "the process whereby individuals achieve increasing control of various aspects of their lives and participate in the community with dignity" (Lord and Hutchison 1993: 7). In the healthcare community, empowerment is closely linked to Kanter's concept of structural power which "mobilises human and material resources to accomplish organisational goals." Reflecting on Kanter's (1993) principle, the study argues that the perception of disempowerment has distorted the migration paths and patterns of the PJEPA candidates as they lost motivation and confidence in the labour scheme. To ensure the sustainability of the labour scheme, structural hindrances to empowerment must be addressed. These constraints include the information infrastructure, resources and capacity building, and access to social structures in the work setting. 
This research employs qualitative techniques to collect and analyse migrant narratives. The researchers conducted semi-structured in-depth interviews with 18 nursing candidates and 18 care worker candidates who have been working in Japan from 2016 to 2018. All their names have been changed to pseudonyms to ensure confidentiality. The authors have also interviewed key officials of the Department of Labour and Employment of the Republic of the Philippines and the Embassy of the Philippines in Tokyo. Other interviewees include the head Japanese language teachers of the EPA Japanese Language Program, nursing professors from the Philippines, public health professors from Japan and a member of the screening committee that recruits EPA workers in Manila. A total of 43 interviewees participated in this study.

This paper begins with a review of the principle of structural empowerment followed by a contextual discussion focusing on Japan's demographic problem and the anticipated impact of the PJEPA on Japan's healthcare sector. The body of the paper presents the narratives of the nurses and care workers, with strong emphasis on the perception of disempowerment in their workplace. The final part revisits the structure of healthcare governance in Japan, drawing attention to policy weaknesses in implementing the PJEPA while providing recommendations on how structural empowerment can contribute to responsible labour migration.

\section{THEORETICAL DISCUSSION ON STRUCTURAL EMPOWERMENT}

Empowerment has various applications in the study of gender, race, citizenship, labour, international development and migration. The concept provides a theoretical understanding on how capabilities translate to meaningful effects and social impacts. More importantly, the concept demonstrates trajectories of power structures as it produces marginalisation and domination. It has become an important conceptual grounding to understand and advocate gender equality (Kabeer 2005), community building (Laverack 2001), social services and civil rights (Hahn 1991), health literacy (Wallerstein 1992), and education (Kreisberg 1992). With its flexible and multidisciplinary lenses, it also contributes to diagnosing the policy failures of an EPA that is supposed to empower economic actors, including health workers. To further analyse the flaws of this labour scheme and understand how it impacts on individual nurses, we examined narratives that reveal migrant experiences on deprivation of opportunities and access to power structures. 
Nursing scholars have explored the concept of empowerment as they explain the frail conditions of health institutions especially in rural places. Empowerment in this context is usually viewed as patient empowerment, highlighting the crucial role of nurses as agents in ensuring the welfare of the client-patients (Elliott and Turrell 1996). In exploring this debate, the relation between patient-centredness and patient empowerment has been widely examined in the healthcare community (Holmström and Röing 2010). Consequently, patients are granted rights and capabilities to manage their wellbeing, and nurses are instrumental to the endowment of these privileges to patients. However, as this paper will expound in the latter part, the capitalistinspired healthcare industries have profoundly employed patient rights and patient empowerment while undermining nurses and care workers' welfare. This has become more problematic, since patients cannot be empowered if the care workers themselves are not empowered (Rodwell 1996). The case of Japan is a clear example of disempowerment of the medical staff, as the healthcare industry, which is composed of private and public hospitals and elderly facilities has given too much attention to the welfare of the elderly patients while disregarding the conditions of the nurses and care workers.

For Rodwell (1996: 307), empowerment is a "process of transferring power and includes the development of a positive self-esteem and recognition." The concept highlights the degree of being entrusted with responsibilities that can be skilfully managed by themselves. More importantly, it implies perceptions of having valuable contribution to one's self, to the workplace or to the community. It therefore anticipates recognition from colleagues and authorities that the job that they accomplished warrants meaningful appreciation. Biron and Bamberger (2010) reintegrate psychological and sociostructural perspectives on empowerment while emphasising the advantages of selective empowerment in affecting productivity and workload, minimising the risks of sacrificing individual well-being.

Studies on nursing empowerment usually refer to Kanter's (1993) organisational empowerment structures which are composed of: (1) information; (2) support including feedback and guidance received from superiors, peers and subordinates; (3) resources; and (4) opportunities for mobility and growth (Ning et al. 2009). These structures serve as key concepts in analysing the narratives of Filipino nurses and care workers. An important key point in the discussion of empowerment posits that access to such empowerment structures facilitates growth and development, and ensures power acquisition (Bish et al. 2012: 2). In fact, a study has proven that nursing empowerment significantly cause positive impacts on patient satisfaction (see Jalali and 
Shaemi 2015). Enjoying organisational trust, these care workers demonstrate affective commitment towards their nursing job (Spence Laschinger et al. 2002). With this established linkage, it is imperative to examine how EPA nurses view their situation and experiences in the context of empowerment (or disempowerment) as nursing migrants. This paper explores the narratives and examines how the provisions of PJEPA and the overall health governance in Japan empower or disempower migrant nurses and care workers.

\section{RATIONALE OF THE PJEPA}

The deployment of Filipino nurses and care workers through the framework of PJEPA has been implemented in light of the demographic problems experienced in Japan. The issue has caused public debates and divisive political campaigns in Japan in the past two decades. Historically, Japan has enjoyed a stable demographic landscape even before the Pacific War. It was only in the 1980s when the government formally recognised aging as one of the key issues for the nation in the 21st century (Ogawa 1996). Since then, Japan realised the appalling implications and negative effects of the greying society.

The aging of Japan's population is accompanied by other detrimental phenomenon - birth rate decline, life expectancy increase and total population drop. The National Institute of Population and Social Security Research (NIPSSR 2014) projected that Japan's population will continue to decrease to only 86.737 million in 2060, which is 32.26 percent lower compared to 2010's population of 128.057 million. The population of young people aged 0-19 is projected to continuously decrease from 37.375 million in 1960, to 22.867 million in 2010 , to only 11.045 million in 2060 . The population of people aged 20-64 will also decrease, from 74.968 million in 2010 to 41.050 million in 2060. Meanwhile, it is expected that the population of the elderly (people aged 65 and above) will continue to grow in 2060, from 29.245 million in 2010 to the projected population of 34.641 million or 40 percent of the total Japanese population. This demographic shift has caused chronic shortages of care workers who run the elderly and medical facilities in Japan.

One of the strategies to recruit nurses and care workers is through a bilateral agreement between Japan and the source country. The PJEPA is a bilateral free trade agreement signed between the Philippine and the Japanese governments in 2006, and entered into force in 2008. The main objective of the PJEPA is "to facilitate and promote the free trans-border flow of goods, persons, services and capital between the Philippines and Japan, and to strengthen the 
existing economic relations between the two countries" (Philexport 2007: 5). One of the salient features of the treaty is the provision on the movement of natural persons, stipulated in the chapter nine of PJEPA. In this section, Japan formally permitted selected professionals from the Philippines to temporarily stay and work in Japan under certain conditions.

Among the groups identified by this provision are the nurses (kangoshi) and care workers (kaigofukushishi). Under PJEPA's Annex 8 (Chapter 9), Filipino nurses and care workers are permitted to enter and work in Japan for the purpose of obtaining the qualifications to become licensed nurses or care workers under the Japanese law. According to the Memorandum of Understanding between the Philippine Overseas Employment Administration (POEA) and the Japan International Corporation of Welfare Services (JICWELS), nurses are allowed to stay in Japan for three years. Within those three years, they are allowed to take the nursing licensure exam three times (POEA 2009). As for the care workers, they are allowed to stay in Japan for four years; also, they are permitted to take the care worker licensure exam once after obtaining three years of work experience. Once the health workers passed their respective licensure exams, they are allowed to extend their stay in Japan.

According to Article 5 of the Japanese Act on Public Health Nurses, Midwives and Nurses, a nurse is defined as a "person who engages in providing care to person with injuries and/or illnesses or postpartum women, or to assist medical treatment under the license of the Minister of Health, Labour and Welfare" (Japanese Nursing Association [JNA] 2016: 9). In order to become a certified Japanese nurse, the following three qualifications must be met. First, a person must be able to complete its 12 years of academic training. Second, a person must complete its years of formal basic nursing education. The duration of basic nursing education varies; four years for colleges and universities, three years for junior colleges and three years for training schools. And finally, the person must pass the national examination to obtain the national license administered by the Minister of Health, Labour and Welfare (MHLW).

Meanwhile, in 2007, the Certified Social Worker and Certified Care Worker Act of 1987 updated the descriptions of a certified care worker and defined a care worker as an individual who has the knowledge, skills and ability to provide and administer a "high-quality, evidence-based nursing care towards his/her care recipient" (The Japan Association of Certified Care Workers n.d.). Among the important duties of care workers are the following: (1) assistance towards nursing care and giving advice regarding nursing care techniques; (2) providing dignified care that may support the care recipient's independence; 
(3) developing a process of care as a healthcare professional; (4) giving support to care recipients that will develop empowerment; and (5) addressing the life changes of its care recipient in order to promote the care recipient's quality of life. ${ }^{1}$ Overall, a care worker is expected to administer physiological assistance, emotional and psychological care to its care recipients, and to provide support in the workplace and among care workers.

In 2009, the Philippines sent its first batch of health workers to Japan. A total of 273 health workers composed of 93 nurses and 180 care workers have been deployed during the first round of the PJEPA implementation (POEA 2009). After almost a decade, the PJEPA has remained extremely conservative in deploying Filipino workers. The 10th batch composed of 40 nurses and 273 care workers arrived in Japan in 2018. In total, 2219 health workers - 546 of whom are nurses while 1673 are care workers - have been employed under the PJEPA scheme. As of 2017 (Escalada 2018), only 74 nurses and 146 care workers were successful in passing their respective licensure exams.

In April 2018, Japan announced the inclusion of caregiving services to the existing trainee system. This would allow more foreign care workers to enter Japan as "trainees" for a period of five years. The Technical Intern Training Programme (TITP) is a programme to develop the technical skills of foreign participants with the hope that it will "advance their careers and contribute to the development of industries and companies through the utilisation of their acquired skills after returning to their home countries" (JITCO 2018). The programme, which is often criticised as a side-door entry for cheap labour (Kamata 2008), has been considered as another scheme to swiftly address the shortages of care workers without encouraging permanent residency in Japan. Meanwhile, the Japanese parliament has approved two visa categories for immigrant workers: one for skilled workers which allows them to stay for five years with no possibility of extension, and another for skilled workers which will allow them to bring their families with possible extension (Suzuki 2018).

\section{HOW PJEPA FAILED: EXPECTATIONS VS. REALITIES}

Policy failure occurs "when a policy does not achieve its stated objective" (Castles 2004: 854). The annual deployment of EPA nurses and care workers seems to demonstrate significant success in achieving the general objective of the PJEPA which is "to liberalise and facilitate trade in goods and services" between Japan and the Philippines. However, the failure is evidenced by the trajectories of migration. These crucial questions should be asked: considering 
their current situation, can they pass the licensure examination? Are they staying in Japan after completing the requirements, undergoing rigid training, and passing the licensure examinations? The narratives indicate the indecisiveness and hesitation of the PJEPA candidates to stay in their workplaces. Perceptions and life plans of the interviewees underscore the "unattractive" working environment in Japan, and the labour enticement offered by Western countries for nurses and care workers.

Japan is not a preferred destination of Filipino nurses. In fact, most of the Filipino nurses prefer countries such as Saudi Arabia, Singapore, the United Kingdom (Makulec 2014) and the United States (Rey 2018). Our interviewees cited varying reasons for choosing Japan over other nursing or care workers' destinations. One of the most cited reasons was Japan's proximity to the Philippines:

I was initially intending to apply to the Triple Win Programme of Germany. When I was applying at the POEA, they were also advertising the JPEPA, so I submitted requirements to both programmes. I got calls from both the Triple Win and JPEPA, but I chose to proceed with JPEPA because Japan is closer to the Philippines, and also I knew that this programme will offer new experiences. (Nicole, 27, Licensed Nurse, Batch 6) ${ }^{2}$

For some, working in Japan means reuniting with other family members. For example, Inah (29, Licensed Care Worker, Batch 3) and Emman (32, Care Worker Candidate, Batch 7) decided to migrate because they have relatives working in Japan. The free language training programme provided by TESDA and the allowance being provided are also some of the reasons our interviewees preferred to work in Japan:

Many nurses want to go to the U.S., but it is very expensive to apply for the NCLEX! Few years ago, you had to spend PhP50,000 to

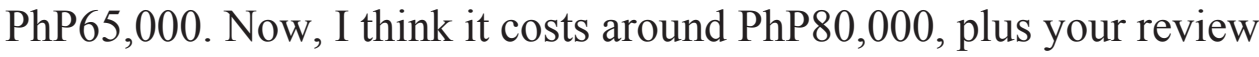
fees and lodging if you attend review sessions in the city. The financial cost of applying to the U.K. was even cheaper. However, when I was about to take the IELTS exam which was required by the U.K., the review classes conflicted with our hospital schedule. So, somebody told me about Japan's EPA programme. They said if we choose Japan, we would undergo language training with allowance, around $\mathrm{PhP} 18,000$. That's a great deal, I thought. (Sabrina, 28, Care Worker Candidate, Batch 8) 
The narratives revealed that most nurses and care workers had very positive expectations of the EPA labour scheme. For them, no destination country has offered such kind of pre-departure incentives and support for the candidates. The only challenge, they thought, was the licensure examinations that they need to pass.

Before leaving the Philippines, nurses and care workers knew that this would be an exciting sojourn for their career. The first few batches of PJEPA's nurses and care workers have attributed their difficulty of passing their respective licensure exams to language barrier. In response to this, the Japanese government redesigned a more comprehensive and intensive language programme to be taken in the Philippines (for 6 months) and Japan (for another 6 months). The 10th batch of the Japanese Language training programme consisting of 42 nurses and 288 certified care worker candidates was conducted in cooperation with The Japan Foundation from 9 November 2017 to 22 May 2018. The 11th batch composed of 41 nurses and 269 care workers completed their training on 21 May 2019. According to the organisers, the objective of the training programme is "to have the candidates obtain the basic knowledge and usage of the Japanese language and study specific vocabulary and essential expressions for nursing and care-taking." ${ }^{3}$ Despite these efforts, some health workers struggled with the language problem. Nelly (27, Licensed Care Worker, Batch 2) recalled the problems with dialect:

In Kagoshima, they have a strong dialect, and that's what makes it very difficult for us. Aside from Japanese, which I haven't mastered yet after six months of language training, I had a hard time understanding them. Our patients, who are usually in their 90 s, use the dialect they are accustomed to in their conversations. I usually ask our patients to speak in standard Japanese.

After painstakingly completing the requirements, some of the nurses and care workers have decided to return to the Philippines. This is a clear drawback on the part of Japan, as they invested resources for the candidates, yet they end up leaving the health institutions after completing all the costly training. One of our interviewees, Rafael (29, Licensed Nurse, Batch 5) did not pass the Japanese nursing national exam but he was able to pass the prefectural exam. In spite of that, he chose not to renew his contract and decided to return to the Philippines. In the case of Nelly (27, Licensed Care Worker, Batch 2) after passing the care worker licensure exam and working for six and a half years as a health worker in Japan, she decided to resign. Majority of the interviewees 
do not plan to stay in Japan for a long time. Jasmine (30, Care Worker, Batch 7) explained why she is hesitant to stay:

As of now, maybe not that long. I would stay but not to the point that [I will stay] for 10 years. It's probably because we experience the opposite of the good life we had during our training in the Philippines. As an OFW, we have to do everything for ourselves, then we have to pay for everything: monthly rent of our apartment, and even our groceries. It's really hard for us because the cost of living here in Japan is high.

Two other nursing trainees, Toni (29, care worker trainee, Batch 6) and Jasmine (30, Care Worker Trainee, Batch 7), who have not yet taken the licensure exam, see themselves staying in Japan for a few more months. In fact, they said that they are only waiting for their contract to end within the year. For those who already passed the licensure exam, they are still "undecided" if they will stay on a long-term basis. Jonathan (29, Licensed Nurse, Batch 5) mentioned that he is still undecided, but later said he intends to stay until he comes up with a "subtle plan" for his future.

The narratives suggest that, overall, the majority of the PJEPA health workers do not see themselves working permanently in Japan. In fact, some of them are no longer motivated to take their respective licensure exams, and they are just waiting for their contract to end. More alarming narratives indicate "indecisiveness" to stay or even take the examinations. This is what Michelle (28, Care Worker Candidate, Batch 8) said during the interview:

I'm no longer interested to pass the licensure examination. I'm giving up, because I am physically exhausted. My body can no longer endure this fatigue. Can you imagine that I've been carrying bodies of my patients, and how many patients in one day?

The indecisiveness to remain in Japan and to continue the migration path can be attributed to the negative experiences during the deployment and training period. Meanwhile, the Department of Labour and Employment (DOLE) of the Philippine Government remains optimistic that reforms can address the unfair schemes of the PJEPA. In our interview with DOLE Secretary Silvestre Bello, he pointed out two main problems faced by Filipino health workers: first, Filipino health workers are having a hard time learning the Japanese language; and second, despite Japan taking advantage of Filipino health workers' services, they do not receive the same benefits as regular employees because their status is that of "a student-worker." In this interview, he expressed his 
hopes that the Philippines will be able to renegotiate for better arrangements regarding the deployment issues:

I was hoping that we could have a better arrangement, that before they are deployed, they should first be trained and given enough proficiency in the Japanese language. Hopefully we can negotiate for better terms for our nurses and our nursing aid. Like what I said, if they work there and work for a probationary period of one year, although they are under probation, they should get the regular [employee] benefits. Even if they do not pass [the exam], they can come back, but in the meantime they [should] get the regular benefits of a regular employee. ${ }^{4}$

While there are minor modifications of the requirements and licensure examinations in the last four years, PJEPA's labour scheme still fails to provide satisfactory working conditions for Filipino nurses and care workers. This is clearly evidenced by the increasing number of returnees, particularly those who plan to return immediately after they finish their contract. The failure of PJEPA to integrate the nurses and care workers into the Japanese healthcare community is a clear loss for both governments and stakeholders that arduously invested resources to facilitate their successful deployment.

\section{LABOUR CONDITIONS OF CARE WORKERS}

Work-life balance contributes to a stress-free employment condition. While some care workers are satisfied with their work environment, the majority of our interviewees feel overworked and even abused by the system. Disempowerment is initially instigated by physical stress, which eventually trigger emotional and psychological fatigue.

With the drastic increase of elderly patients in Japan, the MHLW estimates that an additional 380,000 care workers will be needed by 2025 , the period when the post-war baby boomers reach 75 years or older (Hirano 2017). At present, shortages of care workers persist in several areas, especially outside metropolitan places. Because of these chronic shortages, care workers endure long hours of work and attend to an overwhelming number of patients. This has resulted to physical exhaustion and tremendous anxiety especially for the EPA candidates who are trying to balance their time between working and studying for their respective licensure exams. Such working conditions made Natasha (26, Care Worker Candidate, Batch 9) share her thoughts on physical and emotional exhaustion: 
For four long years, I have endured this kind of job. And although I like the job, my body couldn't tolerate it anymore. I've been undergoing MRI and CT scan almost every year just to get checked that everything is fine. But I still feel something is wrong, I experience all sorts of pain due to physical stress. This job is incomparable to anything that I have done in the Philippines.

The same case applies to Emman (32, Care Worker Trainee, Batch 7) as he talked about keeping a balance between work and study time:

We have class every Monday together with all foreign workers [in the facility]. Once a week, two hours. And then, every day, we also have [time] in our facility to study on our own, two hours a day: 1 hour in the morning, 1 hour in the afternoon. But there are times when we're not following the [schedule] especially when we have a lot of work to do and only a few staff are at work. I have batchmates in different facilities and they say the same thing - either they do not have time for study or they have very little time.

Care workers' duties can be very stressful not only because of their routine to bathe, clean, feed and carry the patients, but also because of the sensitive nature of the caregiving task - they need to stay alert especially when they are looking after senile dementia patients. The increasing number of patients and the shortage of care workers have worsened the situation in the elderly care facility. Jasmine (30, Care Worker Trainee, Batch 7) shared her work routine in the interview:

At work, how many patients are you going to accommodate? Even if there are four (care workers), our situation is difficult because in our group, the most number of patients that we can have is 60. It's hard because you are carrying and bathing a person. They are heavy.

All interviewees agree that the tasks that they do as care workers are very difficult. Physical stress has also affected their social and recreation time, as they prefer to rest during days off instead of travelling around or meeting their friends in Japan. For the devout Christians, they no longer attend Sunday masses or Christian services because they are either too tired, or they need time to review for the examination. This cycle of stress makes them feel disempowered as they find discomfort within the working environment. Also, these care workers who are mostly licensed nurses in the Philippines confront emotional stress caused by the experience of deskilling as they perform jobs 
that are not usually given to registered nurses in other countries. Throughout the interviews, they repeatedly mentioned the difficult and dirty jobs that they do: assisting in toilet activity, cleaning patients' bodies, cleaning washrooms and toilets, carrying patients and lifting heavy equipment in the facility. One of our interviewees who had already returned to the Philippines even before taking the care worker licensure exam explained that there were "strange tasks" given to them which are definitely beyond the responsibility of a care worker. Examples of these tasks, according to James (28, Care Worker Candidate, Batch 5) are laundry duties and folding of linens, sorting garbage, cleaning of roof before the scheduled inspection of the authorities, and angel care (sanitising a person who just passed away). Preparing medicines and doing nursing notes which should be done by nurses were also assigned to candidate care workers.

Furthermore, facilities experiencing such shortages tend to ignore the rights and conditions of their workers, especially the EPA candidates. Thus, tensions arise when care workers request vacation leave or even emergency leave. There are even administrators who are not familiar with the situation of the EPA workers, and the general system of the labour scheme. An interviewee narrates the ignorance of her supervisors on the contract that she signed:

The administrators of the facility are not even aware that we have signed a contract. Also, our supervisors do not really know our situation as EPA care workers. When I asked permission for a 10-day leave, my boss asked why I would leave that long, while Japanese workers normally do not do that. I said that's allowed in our contract, and he became more confused. (Claudine, 30, Care Worker Candidate, Batch 9)

Even leaders of the elderly facilities are not well-informed about the PJEPA scheme. Spence Laschinger et al.'s study emphasises the benefit of positive supervisor relationship and effective leadership in "creating conditions that result in a committed workforce" (Spence Laschinger et al. 2009: 228). The said study argues that effective unit leadership encourages a highly motivated healthcare staff. The narratives of our health workers, however, reveal lapses in leadership and communications in some facilities. Clearly, there seems to be a lack of coordination between the administrators of the care facilities, the JICWELS and other implementers of the PJEPA. Since the new stipulations in the EPA pose tremendous challenge to the hierarchy and old systems in elderly institutions, it is imperative for the state to orient, monitor, and provide technical support and assistance to elderly facilities that hire EPA candidates. 
The Japanese government must begin to introduce reforms in order to support the integration of foreign care workers to the healthcare setting in Japan.

While most of the interviewees in this study shared negative experiences, it should be noted that some care facilities have done better practises to empower their workers. Ogawa (2016) explains how some facilities train the care workers to take up managerial positions, provide language review sessions, maintain good working relations between Japanese and EPA candidates, and even help the host community to understand the culture of EPA candidates. In these facilities that provide holistic support to the care workers, elderly patients have developed a positive perception on the immigrant health workers. Also, interviewed candidates in such facilities have a more positive outlook on the labour scheme, hence the possibility of long-term stay.

\section{STAFFING ISSUES: DESKILLING OR FALSE EXPECTATIONS?}

The rapidly aging population of Japanese society is the major driving force of nursing reform in Japan. In fact, nursing, health and social welfare policy in the country has focused on developing the capacity of the service delivery system and providing comprehensive health and medical services, including prevention and rehabilitation in order to maximise health in the elderly, assure appropriate service utilisation, and control costs (Primono 2000). The Public Nurse, Nurse and Midwife Law of 1948 in Japan specified the two roles of the nurses: first, to care for the sick, disabled, and women after childbirth, and second, to assist physicians with examinations and treatments. The law clearly restricts nursing duties and upholds the authoritative duties of a doctor. It should be noted that in the Philippines, this perception has long been altered by the idea that RNs have distinct roles in the medical community. One of the nursing professors who we interviewed explained that "while medical doctors are trained to treat the disease, nurses are assigned to manage human responses in the course of the treatment." Republic Act 9173 or the Philippine Nursing Act stipulates that nurses, as independent practitioners, are primarily responsible for the promotion of health and prevention of illness. ${ }^{5}$ As members of the health team, they are expected to collaborate with other health care providers for the curative, preventive and rehabilitative aspects of care, restoration of health, alleviation of suffering, and when recovery is not possible, towards a peaceful death (Venzon and Venzon 2005). 
Filipino nurses, as previously mentioned, are deskilled as nursing assistants until they pass the licensure examination. However, some narratives claim that the situation is even worse:

In our facility, we are treated neither as nurses nor nursing assistants. We are basically helpers. (Marie, 31, Nurse Candidate, Batch 7)

Our nursing career here is dead. You are lucky if one Japanese nurse invites you to do some rounds and check vital signs, that's the only time that you experience being a nurse. But most of the time, you change diapers, clean patients' rooms, and carry patients. How do we survive each day? We just enjoy it by talking with patients. There's no professional growth here. You won't learn anything. And even if you ask the Japanese nurse about the case of a patient, the nurse is either too busy, or she is also not aware of the patient's medical case. (Maxine, 28, Nurse Candidate, Batch 8)

The degree of deskilling was the central theme in almost all the narratives of Filipino nurses that we interviewed. Interviewees expected that their initial tasks as nursing assistants would be short-term and transitory, but they realised that the overall healthcare design places them at the bottom of the hierarchy, disabling their capabilities as trained nurses, and prolonging their deskilled duties as helpers.

As trained nurses in the Philippines, EPA candidates are aware of the nursing protocols on healthcare. They are surprised, then, that they are assigned to patients whose background and medical cases are not disclosed to them. The interviewee narrated:

We don't know the case of each patient. You guess, but you're not sure of his/her condition. And you ask your patient to take whatever medicine as instructed, but you don't have any idea about that medicine. (Elizabeth, 35, Nurse Candidate, Batch 9)

EPA candidates feel that their unfamiliarity to the medical background of the patient is an experience of professional disempowerment. As nurses, they know that the practise of nursing is only effective if they know the situation of the patient. This lack of information about the patient makes them incapable of performing their best as care workers or nurses. Nurses were simply asked to obey the instructions from their supervisors. Thus, Elizabeth thinks that: 
This programme is definitely not advisable for nurses who are going abroad for the first time. Definitely not a good experience, unless you pass the exam. Otherwise, you're here for nothing, and all the technical skills that you learned from the Philippines will be forgotten. You're going to be disappointed because your training (in the Philippines) has given you different perspectives and expectations of nursing duties, but when you're here (in Japan) you're basically a helper.

The narratives of the EPA nurses highlight the perception of being structurally and psychologically disempowered on several aspects. As they perform their duties, they cannot find meaning and purpose in the things that they do. In the end, they feel that they have lost the dignity of their profession as nurses. Because of these negative experiences, Alice (29, Nurse Candidate, Batch 8) wants to bring this up to the authorities:

I suggest that those hospitals that cannot comply with the standards of the EPA should not participate in the programme. They shouldn't hire Filipino nurses... Because some of these facilities are simply hiring foreign workers because they are understaffed. Well, the consequence is that their foreign workers really suffer, similar to what we experienced... We came here for career advancement and career growth, but it seems that those goals are just impossible to be fulfilled here.

A Japanese professor from a public health institution explains that the recent frameworks (e.g., EPA, trainee system, new visa system) fail to address the root problems of healthcare human resources in Japan. ${ }^{6}$ According to her, accommodating nurses and care workers without fair agreements would hurt both sending and host countries, as what the narratives have presented. Before pursuing or expanding these new frameworks, it is important to improve the working conditions of the nurses first. She argues that the government must shift its focus from "addressing the nursing shortages" to the "problems of turnover and work retention." She also suggested that governments involved in EPA should consider the World Health Organization (WHO) Global Code of Practise on the International Recruitment of Health Personnel, an international guideline that promotes fair and mutually beneficial circulation of health workers.

Our Japanese interviewees have claimed that local nurses and care workers in Japan have continuously suffered due to bad working conditions. A study of Eltaybani et al. (2018) reveals the negative images held against 
long-term care facilities as Japanese nurses perceive such facilities as places for "miyako-ochi" or castaways, a workplace that "they cannot be proud of." These perceptive images of Japanese elderly facilities have confirmed the lack of institutional support provided by the government to improve the quality of care services and to uplift the morale of the nurses in such institutions. For the nurses, the JNA has observed the continuous increase of those leaving the nursing practise and profession. According to the JNA report, this is due to the "demeaning work environment that makes it difficult for the nursing personnel to continue working" (JNA 2016: 15). Other cited reasons for the unpopularity of the nursing practise are the irregular work shifts, long working hours, burden of night shift, heavy responsibilities and poor treatment. The report of the JNA uncovers the difficulties and challenges of disempowerment among both local and foreign nurses in Japan. Another interview of a Public Health professor from a Japanese university supports this claim, as she underscores the "lack of safety net and support from co-workers" which hinder career development for both local and foreign health workers.

While it is important to listen to the voices of Filipino nurses, the healthcare structure and nursing culture in Japan should also be understood within the perspective of Japanese care clientele. A study by Tsujimura et al. (2016) clarifies the significant differences of Japan's nursing practise if compared with other countries' nursing system. Practise expectations in Japan involve "basic nursing tasks" including bed baths and toileting. In addition, the study has also found that the Japanese nursing culture relies on non-verbal communication "to deliver thoughtfulness and perceptiveness." Finally, nurses in Japan exhibit deference to doctors and colleagues in order to maintain harmony in the workplace. With these practises, it can be noted that some tasks being complained by Filipino EPA candidates are really part of the nursing duties in Japan. Thus, the perception of deskilling indicates structural gaps and incompatible frameworks between the Philippine and Japanese nursing systems. The perceptions of deskilling and unfair treatment to Filipino nurses hinder the achievement of structural empowerment. Such perceptions are fuelled by the lack of information and contextual understanding of crosscultural nursing practices. As a result, this widens the gap between the expected duties and actual practises in giving care. Furthermore, it depreciates the sense of dignity and meaning of the nurses as they fulfil care labour. 


\section{RETHINKING THE DIGNITY OF CARE LABOUR}

The PJEPA and other EPAs are manifestations of Japan's compliance to the global neoliberal order, which reinforced a "hierarchical regime of social reproduction based on gender, nationality, class, ethnicity, and/or race" (Onuki 2011: 61). In this viewpoint, the marketisation of care work has degraded such reproductive jobs, creating a medical space where flexible and low-wage workers endure an insecure work environment. The value of dignity in the work-life of health workers has caught the attention of nursing scholars as they saw the remarkable level of migration and transnational mobility of nurses. Since this concept compels favourable work conditions of individual nurses, it has often been undermined in countries like Japan where chronic shortages necessitate tremendous hard work and patience. Lawless and Moss (2007: 225) explain that this principle has often been disregarded "partly in approaches that privilege patient dignity over nurse dignity and which rely on altruism and self-sacrifice of nurses to sustain patient care in environments dominated by cost-control agendas." This is the actual situation in understaffed elderly and medical facilities, particularly in rural areas in Japan.

Disempowerment is experienced by demeaning the dignity of professional labour. While the phenomenon of deskilling has been a relentless part of the migrant journey for many types of workers, especially women (Raghuram and Kofman 2004), its impact on individual well-being cannot be undermined. In some cases, it is a phenomenon that can be regarded as a form of discrimination (Siar 2013). For instance, Daisy (32, Licensed Nurse, Batch 3) expressed her concerns about the negative perception of the Japanese to the Filipinos and other foreign migrants.

There are instances that some of the Japanese nurses would underestimate us because of the image of Filipinos as professional entertainers rather than as nurses.

Benjamin (30, Licensed Nurse, Batch 5) also realised that the salary of their Japanese counterparts is usually higher than that of the foreign workers:

In my former hospital, I noticed that there is a difference in salary between the Japanese and Filipino nurses. The Japanese nurses receive higher compensation compared to us, but we share the same amount of workload. 
Filipino nurses and care workers are aware that wage discrepancy should not happen, as the pre-departure seminar and PJEPA orientation program speakers told them that they will receive the salary equivalent to those being received by their Japanese counterparts. According to a Japanese member of the EPA screening team for the 11th batch, the Japanese government has been trying to make the system as fair as possible, and salary/compensation issue has been clearly resolved in the past discussions. The official reiterated that Filipinos get the same or equivalent salary of Japanese nationals who are doing the same tasks. The interviewee assured us that this policy is strictly implemented. ${ }^{7}$

Tensions arise when some Filipino nurses voice out their concerns or complain about the unfair workload and compensation. Discrimination against foreign nurses, according to the interviewees, is a part of their everyday work life. This is an important point, as the overall consequence determines how Japan can retain foreign nurses for a long time. More often, the experience made them realise that leaving the facility is the best option:

If given a chance, I will transfer to another facility. Or I will just look for another job that has nothing to do with nursing. I want to stay here in Japan because of its proximity to the Philippines, but perhaps another job? (Wilma, 30, Nurse Candidate, Batch 7)

The statement above is crucial in projecting the migration paths and patterns of health workers. In the case of Wilma, even if she passes the examination, she still plans to move to another facility or look for a job that is not related to nursing. This mentality is common among care workers who find their work environment unsatisfactory. In the long-term care sector, job retention has become more challenging as it requires better career prospects and better paid jobs (Fujisawa and Colombo 2009).

Interestingly, the negative experiences that led to disempowerment are sometimes appeased by the patient's appreciation and gratitude. Anna (30, Nurse, Batch 5) and Ina (29, Licensed Care Worker, Batch 3) enthusiastically shared their experiences with their Japanese patients:

Japanese patients, especially the elders, treat us well. They take the time to explain what they want to say when we are having difficulty in understanding them. They also appreciate and prefer Filipino nurses because we are more warm and caring (Anna). 
It was a difficult job, but I am happy. I'm happy when I see them happy with the kind of care service that I render, especially when they say "arigatou." It feels good because they appreciate the care I'm giving them (Ina).

For the interviewees, this has often uplifted their dignity as nurses, and lessened the emotional impact of disempowerment. Japanese patients, according to the narratives, are very appreciative of Filipino nurses and care workers - they value the care and emotional warmth that Filipinos demonstrate through care work. Hence, these patients often prefer Filipino nurses and care workers because of these positive attributes. Often, Filipino nurses and care workers are assigned to patients with dementia and other mental health disorders. Since Filipino nurses and care workers fully understand this psychological condition, they become more patient in dealing with impolite and irate patients.

The degrading dignity of labour has manifested in the narratives that spoke about care workers and nurses who cannot fulfil the "human touch" of nursing care, as what they have been trained to do in the Philippines. The system has reduced them to automatons who have a list of tasks that should be accomplished mechanically in a given period of time. As many of them repeatedly claim, they were "treated like robots."

Japan has also invested in robotics to aid in nursing care. Supplementing human resource development, care entrepreneurs have relied on robot applications for assisting the elderly, monitoring health and safety, and providing them with companionship. This innovation has provided efficiency and accuracy in providing care support, albeit some ethical concerns of utilising machines for such purposes (Sharkey and Sharkey 2012). Nonetheless, the mechanisation of care work has made advances in revolutionising modern nursing services, thanks to private corporations that highly invested on research and development. For instance, Sanyo Electric has created a "human washing machine," while Sony has popularised the production of robot "companions" (Parks 2010).

\section{PJEPA AND HEALTHCARE GOVERNANCE}

As demographic crisis looms in the next decades, social and economic infrastructure that support Japan's elderly care system warrant sustainable and meaningful reforms. Therefore, this paper proposes a thorough review of the EPA, particularly the labour scheme for the entry of nurses and care workers. With its provisions that almost made it impossible to retain nurses and care 
workers, the scheme has become a political tool rather than a strategic solution to address the demographic problem. Its underlying rhetoric to welcome foreign workers sounds meaningful in a symbolic sense, as it has become a diplomatic gesture to promote international cooperation (Takahashi 2018). Some analysts have even claimed that the purpose is for economic benefits, specifically to "facilitate the export of Japanese merchandise" (Lan 2018: 5). Such tradecentredness and lack of foresight and strategic vision have prolonged the "temporariness" and flexibility of the care workers, as they are not expected to stay permanently. It is also clear that there are serious gaps between the interpretations of the provisions in the PJEPA between the Japanese and Philippine governments. These inconsistencies in the initial negotiations until the implementation period have worsened over time, causing vague understanding of the agreement from the level of the topmost government negotiators down to the facility managers and administrators (Hosono 2011).

To provide more alternatives for elderly care, the Japanese government implemented the Long-term Care Insurance Law (Kaigohokensho) in April 2000. The law encourages care-giving of the elderly at home instead of congesting the welfare facilities (MHLW 2002). This set-up was favoured by most Japanese because it preserves close family ties without causing much difficulty to the family members. Living at home with their family or relatives, the elderly patients are presumed to be more comfortable, relaxed and free from social criticisms. Under the Long-term Care Insurance Law, elderly patients are: (1) supported by the state to become "independent"; (2) recipients of health, medical and welfare services from diverse agents of their choice; and (3) compulsorily insured once they reach the age of 40 (NIPSSR 2014).

The strategies of the Japanese government have been proven to be effective in solving the immediate shortages without threatening the conservative tenets of Japan's ethnic homogeneity. Before considering immigrants, the initial approach is to recruit more care providers in the local setting. Moreover, the government has carried out campaigns to encourage women and those who are "not currently in employment, education or training" (Vogt 2018: 23). It is also interesting that community-oriented approaches have been promoted to enhance elderly participation within the neighbourhood setting. In this approach, neighbourhood associations serve as a dynamic facilitator of various activities such as promotion of "lifelong learning," raising awareness on health issues, and partnering with local government in carrying out public services (Vogt 2018: 25). 
While the Long-term Care Insurance Law and community approaches seemed to demonstrate positive outcomes, the increase of elderly patients require more long-term, strategic approaches. The EPA and other immigration schemes offer viable solutions. Indeed, the entry of nurses and care workers through the EPA has been a historic success as Japan finally opened its doors to foreign workers, but is also exhibiting policy failure as it disempowers the care sector, preventing them from realising their labour dignity as nurses and care workers. Multiple and complex factors have shaped the PJEPA into its current faulty schemes. The most crucial, as we argue in this paper, is the overall migration management system of the host country that failed to provide opportunities for labour empowerment.

The narratives of EPA nurses and care workers emphasise the experiences of disempowerment reproduced by Japan's healthcare and migration governance. Since 1980, the Japanese Government has been studying possible steps to minimise the negative implications of the demographic shift through conservative approaches. Aside from the improvement of a public pension scheme, the government has taken steps to intensify health promotion, preventive medical treatment and rehabilitation. Japan's policies for the aged focused on health education, health counselling, health screening, physical rehabilitation, home visits for health guidance, establishment of special facilities and the training of health workers. In spite of these strategies, a Japanese nursing university professor argues that these programmes are one-sided as it only promotes patient empowerment. ${ }^{8}$ Equally important is care provider empowerment, hence the necessity to uphold innovative strategies to ensure sustainable elderly health. She suggested reforming the nursing and public health education system to accommodate more foreign students who can study and work in Japan. According to the professor, providing scholarships and promoting nursing education to foreign students may significantly increase Nihongo-speaking foreign nurses and care workers who can transform Japan's healthcare system into a globalised nursing sector.

In a separate interview with a distinguished Japanese professor of public health in Aichi, ${ }^{9}$ crucial issues on culture have been discussed:

We cannot speak directly. We have to express ourselves in a different way. Meanings change when we speak to patients, doctors, and colleagues. Cultural gap is always a problem for foreign workers. In our profession, communication is important. Japanese language is very important. Cultural understanding is important. 
Furthermore, the said professor believes that foreign nurses should be accepted and integrated into the healthcare community. This will entail language and cultural learning. The role of the host facility is crucial, yet these facilities do not have the capacity and expertise to implement language and cultural training. Thus, state support must reach these facilities to monitor their support mechanism to the nurses and care workers. During the 2019 EPA recruitment program, a member of the screening committee has also mentioned that "the rate of matching is getting lower every year because the number of facilities is increasing while the number of candidates is not changing." 10 The increasing costs of the EPA and the difficulties to match candidates are clear indicators that the PJEPA scheme is not sustainable.

In reviewing the terms of the PJEPA, it is worthy to examine the schemes of the Triple Win Project of Germany and the Philippines. Like the PJEPA, the Triple Win Project is an agreement on the recruitment and employment of Filipino nurses in Germany. A salient feature of the Triple Win that Japan can adopt is the professional and orientation training provided to Filipino nurses before and during their deployment in Germany (POEA 2013). Deutsche Gesellschaft für Internationale Zusammenarbeit (GIZ) provides cultural training to Filipino nurses to get themselves familiarised with norms and practices, especially on German health care facilities. To provide them with deeper understanding of German culture, as well as to adjust to their new environment, Filipino nurses are paired with local nurses (Triple Win Bewerber Information 2013). Another important feature of the Triple Win that PJEPA can look into is the involvement of trade unions or labour organisations. In the Triple Win Project, two trade unions are involved in implementing and montoring the Triple Win Program, the Public Services Labour Independent Confederation (PSLINK) which is based in the Philippines, and the Vereinte Dienstleistungsgewerkschaft (German United Services Trade Union) which is based in Germany. These trade unions can review job descriptions, and monitor the recruitment and deployment of Filipino nurses under the programme as they conduct periodic visits to the workplaces of the Filipino nurses. These unions also provide membership privileges to their Filipino nurses members (Gencianos 2017; Beck 2017).

\section{CONCLUSION}

The findings of this research reveal the disempowerment of nurses and care workers in upholding their professional status. The narratives uncover 
strong sentiments and perceptions of disempowerment as health workers confront the challenges in adjusting to the work environment, coping with the communication barriers, and performing the tasks as trainees. We argue that the mechanisms causing disempowerment are reflective of the limits of healthcare governance. Specifically, we observed that the shortcomings are related to: (1) the ineffective monitoring of elderly facilities throughout Japan; (2) the lack of support to develop capacities in honing professional skills; and (3) the weak information infrastructure that causes a damaging gap between migrant expectations and workplace realities. Overcoming these problems entails policy reforms of the labour scheme that would improve the systems and mechanisms of standardising the workplace policies, improving the information infrastructure from pre-deployment to actual employment, and enhancing the mechanisms of upskilling and developing professional skills and healthcare practises.

Further analysis suggests that the root problem lies within the healthcare governance system that fails to regulate the facilities in supporting and "empowering" their employees. Instead of providing incentives for those facilities, the Japanese government seems to overregulate the recruitment process that result to the limited entry of foreign health workers. Ironically, while the Japanese government imposes stringent qualifications and requirements, it is lenient in monitoring the actual implementation of the EPA in the worksite. It also fails to ensure good labour relations between the host facility and the care workers. In fact, the government takes a non-interventionist position when it comes to employment contracts and training regulations of the accepting institutions (Asato 2012). This poses a major problem for both the EPA workers and the host institution. First, some accepting institutions need further guidance in crafting an employment contract that complies with all the agreed provisions of PJEPA. Second, most accepting institutions do not possess the technical capabilities and resources in providing professional language training and licensure examination review. Since all these arrangements and schemes have not been explored by accepting institutions, they usually resort to "trialand-error approaches" (Asato 2012: 662). These mechanisms are reflective of the government's "fragmentary nature" of immigration policies, as it often prioritises "cross-cutting policy agenda and various policy actors at all times" (Akashi 2018: 24).

The Japanese healthcare system, which is usually characterised by its successful implementation of universal coverage of health insurance, has been regarded as one of the best in the developed world (Jones 2009). However, it is 
also seriously dealing with fiscal challenges as healthcare costs continuously increase due to the burgeoning number of elderly patients. The welfare state has expanded, with the government taking an active role on social care and policy provisions that support family-work reconciliation (Peng 2002). Over the course of time, the national government has become more indecisive and uncoordinated in terms of its support to the elderly facilities. These facilities have lost not only its financial capacity to sustain a strong workforce, but also its strategic directions and organisational commitment to empower not only their elderly patients but also their nurses and care workers. As observed by Matsuyama (2014), one of the major flaws of Japan's healthcare governance is the fragmented and uncoordinated funding system and care-delivery system, which clearly cause the entire mechanism to malfunction. This year, the Japanese government has opened another scheme for care workers under the TITP. ${ }^{11}$ While the key advantage of this set-up is the Japanese language proficiency requirement, the system does not address the problems on scheduling, working conditions and prospects of permanency. The new scheme proves to be another experimental set-up that perpetuates the precarious conditions of health workers. This would take a toll on Japan's elderly care industry; and without meaningful reforms, the PJEPA programme and other EPAs will only be an economic and political gesture without significant impact on the government's agenda of maintaining growth and stability amidst the demographic crisis.

\section{ACKNOWLEDGEMENTS}

The authors would like to thank Ms. Maria Donna Ballesteros for the valuable comments on the manuscript. We also thank Ms. Gracielle Vargas for proofreading the paper. We are grateful to the interviewees including the EPA candidates, government officials, and Filipino and Japanese nursing scholars.

\section{NOTES}

* Ron Bridget Vilog, $\mathrm{PhD}$, is an associate professor at the International Studies Department of De La Salle University, Manila, Philippines.

** Ma. Keren Happuch Arroyo is pursuing Master of Arts in International Studies major in Asian Studies at De La Salle University, Manila, Philippines. She is also a lecturer at San Beda College Alabang, Philippines.

*** Tezla Gael Raquinio is pursuing MA in International Studies major in Asian Studies at De La Salle University in the Philippines. She has worked as a Research Assistant in the same Department. 
1 Other duties indicated in the 9187 law are: (1) administering support for the lifestyle that the care recipient wishes to experience, may it be in a facility or at home; (2) understanding the dynamics in the workplace as the care worker is expected to bolster collaboration among its fellow care workers; (3) communicating effectively, orally and writing-wise, toward their care recipient and its family members; (4) understanding the workings in the system so that the caregiver may respond to the needs of the community; and finally (5) must be playing core roles in the workplace.

2 PJEPA is also known as JPEPA, which stands for Japan-Philippine Economic Partnership Agreement. The Ministry of Foreign Affairs of Japan still refers to the treaty as JPEPA.

3 This quotation is from the announcement of Japan Foreign Ministry office during the Japanese language training programme for nurse, certified care worker candidates. Published by Inquirer.net on Tuesday, 13 August 2019.

4 Interview with the Secretary of the Philippine Department of Labour and Employment (DOLE), Silvestre Bello III on 6 December 2016.

5 Republic Act 9173, otherwise known as the Philippine Nursing Act, was enacted on 21 October 2001. It stipulates that nurses must have a salary schedule of not less than grade 15. However, this was changed by then President Macapagal Arroyo to grade 11 in 2009 through the Executive Order Number 811. In 2015, Ang Nars Party-list filed a petition to bring back the original salary grade. It was only in February that hearing of the petition began.

6 Interview with a public health and medicine professor at Nagoya City University, Japan on 13 November 2018.

7 Interview with a member of the Screening Committee of EPA, 11th and 12th batch, conducted on 25 July 2019.

8 Interview with a Japanese nurse and professor of public health on 20 June 2019.

9 Interview conducted with a Japanese professor of nursing and public health on 23 May 2019.

10 Interviewee same as note 7.

11 According to DOLE Department Order No. 188-B, or the guidelines on the implementation of the organisation for TITP in relation to the technical intern training (TIT) for care workers job category, trainee must have completed one of the following language proficiency requirements: (a) pass N4 level of JLPT or its practical test equivalence; (b) score 350 or more in the E-F level test or 400 or more in the A-D test of the J.Test (Test of Practical Japanese) implemented by the Japan language Examination Association or its practical test equivalence (if the trainee scores 400 or more in the A-D test, the trainee automatically fulfils the language proficiency requirement for 2 nd year of TIT); and (c) pass at least level 4 of the Japanese language NAT-TEST or its practical test equivalence. 


\section{REFERENCES}

Akashi, J. 2018. Immigration policy in contemporary Japan: The dilemma between control and coexistence. In Thinking beyond the state: Migration, integration, and citizenship in Japan and the Philippines, ed. Zulueta, J., 3-31. Manila: De La Salle University Publishing House.

Asato, W. 2012. Nurses from abroad and the formation of a dual labor market in Japan. Southeast Asian Studies 49 (4): 625-669, https://doi.org/10.20495/tak.49.4_652.

Beck, H. 2017. Germany-Philippines bilateral agreement on health workers. Paper presented at the Fourth Global Forum on Human Resources for Health, 13-17 November, Dublin.

Biron, M. and Bamberger, P. 2010. The impact of structural empowerment on individual well-being and performance: Taking agent preferences, self-efficacy and operational constraints into account. Human Relations 63 (2): 163-191.

Bish, M., Kenny, A. and Nay, R. 2012. Perceptions of structural empowerment: Nurse leaders in rural health services. Journal of Nursing Management 22 (1): 29-37, https://doi.org/10.1111/jonm.12029.

Castles, S. 2004. The factors that make and unmake migration policies. International Migration Review 38 (3): 852-884, https://doi.org/10.1111/j.1747-7379.2004. tb00222.x.

Elliott, M. A. and Turrell, A. 1996. Dilemmas for the empowering nurse. Journal of Nursing Management 4 (5): 273-279, https://doi.org/10.1046/j.1365-2834.1996.02303.x.

Eltaybani, S. et al. 2018. Factors related to intention to stay in the current workplace among long term care nurses: A nationwide survey. International Journal of Nursing 80: 118-127, https://doi.org/10.1016/j.ijnurstu.2018.01.008.

Escalada, M. R. C. 2018. Snapshot of labor market information. https://polotokyo.dole.gov. ph/wp-content/uploads/2018/03/LMI-Snapshot-2018-1.pdf (accessed 7 November 2018).

Fujisawa, R. and Colombo, F. 2009. The long-term care workforce: Overview and strategies to adapt supply to a growing demand. OECD Health working papers, OECD Publishing, https://doi.org/10.1787/225350638472.

Gencianos, G. 2017. Public service international. Paper presented at Third Informal Thematic Session: International Cooperation and Governance of Migration in All its Dimensions, 19-20 June, Geneva.

Hahn, H. 1991. Alternative views of empowerment: Social services and civil rights. The Journal of Rehabilitation 57 (4): 17-19.

Hirano, Y. 2017. Foreign careworkers in Japan: A policy without a vision. Nippon.com, 13 February. https://www.nippon.com/en/currents/d00288/ (accessed 14 November 2018).

Holmström, I. and Röing, M. 2010. The relation between patient-centeredness and patient empowerment: A discussion on concepts. Patient Education and Counseling 79 (2): 167-172, https://doi.org/10/1016/j.pec.2009.08.0008.

Hosono, Y. 2011. Accepting nurse and certified care worker candidates in Japan: How a bilateral policy decision is implemented at the administration level. Yokohama Journal of Social Sciences 16 (3): 340-355. 
Jalali, Z. and Shaemi, A. 2015. The impact of nurses' empowerment and decisionmaking on the care quality of patients in healthcare reform plan. Human Resource Management 2 (9): 33-39 (accessed 7 November 2018).

Japanese Nursing Association (JNA). 2016. Nursing in Japan 2016. https://www.nurse. or.jp/jna/english/pdf/nursing-in-japan2016.pdf (accessed 9 April 2019).

Japan International Training Cooperation Organization (JITCO). 2018. JITCO Official Website, www.jitco.or.jp/english/overview/itp/index.html (accessed 1 November 2018).

Japanese Association of Certified Careworkers. n.d. http://www.jaccw.or.jp/ home/index_en.php?fbclid=IwAR3ESov9qyjkj236eTIsdUOpxrRr1 gQACfnfDWdxmcmMy6S1UzDzzTK464 (accessed 9 April 2019).

Jones, R. 2009. Health-care reform in Japan: Controlling costs, improving quality and ensuring equity. Working paper no. 739, OECD Economics Department, OECD Publishing, Paris, https://doi.org/10.1787/220005270870.

Kabeer, N. 2005. Gender equality and women's empowerment: A critical analysis of the third millennium development goal. Gender and Development 13 (1): 13-24, https://doi.org/10.1080/13552070512332273.

Kamata, S. (2008). Japan's internship training program for foreign workers: Education or exploitation? The Asia-Pacific Journal: Japan Focus 6 (7): 1-8.

Kanter, R. 1993. Men and women of the corporation. New York: Basic Books.

Kawaguchi, Y. et al. 2012. Exploring learning problems of Filipino nurse candidates working in Japan: Based on the results of a practice National Board Examination of Japan Given in English. Southeast Asian Studies 49 (4): 643-651.

Kreisberg, S. 1992.Transforming power: Domination, empowerment, and education. New York: SUNY Press.

Lan, P. C. 2018. Bridging ethnic differences for cultural intimacy: Production of migrant careworkers in Japan. Critical Sociology 44 (7-8): 1-15, https://doi. org/10.1177/0896920517751591.

Laverack, G. 2001. An identification and interpretation of the organizational aspects of community empowerment. Community Development Journal 36 (2): 134-145, https://doi.org/10/1093/cdj/36.2.134.

Lawless, J. and Moss, C. 2007. Exploring the value of dignity in the work-life of nurses. Contemporary Nurse 24 (2): 225-236, https://doi/10.5172/conu.2007.24.2.225.

Lord, J. and Hutchison, P. 1993. The process of empowerment: Implications for theory and practice. Canadian Journal of Community Mental Health 12 (1): 5-22, https://doi. org/10.7870/cjcmh-1993-0001.

Makulec, A. 2014. Philippine's bilateral labour arrangements on health-care professional migration: In search of meaning. ILO Asia Pacific working paper series, ILO Country Office for the Philippines. http://www.ilo.org/wcmsp5/groups/public/---asia/--ro-bangkok/---ilo-manila/documents/publication/wcms_320609.pdf (accessed 14 November 2018).

Matsuyama, Y. 2014. Aging and the governance of the healthcare system in Japan. Bruegel working paper, https://www.econstor.eu/bitstream/10419/126725/1/812418735. pdf (accessed 14 November 2018). 
Ministry of Health and Labor (MHLW). 2002 The long term care insurance system. MHLW, https://www.mhlw.go.jp/english/topics/elderly/care/2.html (accessed 14 November 2018).

National Institute of Population and Social Security Research (NIPSSR). 2014. Social security in Japan. NIPSSR, http://www.ipss.go.jp/s-info/e/ssj2014/PDF/ssj2014. pdf (accessed 14 November 2018).

Ning, S. et al. 2009. The impact of nurse empowerment on job satisfaction. Journal of Advanced Nursing 65 (12): 2642-2648, https://doi.org/10.1111/j.13652648.2009.05133.x.

Ogawa, N. 1996. When the baby boomers grow old. Japan Echoe, Special Issue, 17-18.

Ogawa, R. 2016. Demographic change and migration of careworkers: Sate, care facilities, and migrants. In Japan's demographic revival: Rethinking migration, identity, and sociocultural norms, ed. Nagy, S. R., 83-112. Singapore: World Scientific.

Onuki, H. 2011. The global migration of care labour: Filipino workers in Japan. In Feminist ethics and social policy: Towards a new global political economy of care, eds. Mahon, R. and Robinson, F., 60-76. Vancouver: UBC Press.

Parks, J. 2010. Lifting the burden of women's care work: Should robots replace the "human touch"? Hypatia 25 (1): 100-120, https://doi.or/10.1111/j.1527-2001.2009.01086.x.

Peng, I. 2002. Social care in crisis: Gender, demography, and welfare state restructuring in Japan. Social Politics: International Studies in Gender, State \& Society 9 (3): 411-443, https://doi.org/10.1093/sp/9.3.411.

Philexport. 2007. Q \& A Primer: Understanding JPEPA. Philippine Exporters Confederation, http://www.philexport.ph/c/document_library/get_file?uuid=23c2bd96-d728436d-9b6c-b56dc78c4b16\&groupId=127524 (accessed 14 November 2018).

POEA. 2009. News release: Recruitment of nurses and caregivers for Japan to start soon. POEA, http://www.poea.gov.ph/news/2009/01-3.pdf (accessed 14 November 2018).

. 2013. Triple Win: Placement of qualified nurses from the Philippines in Germany. POEA, http://www.poea.gov.ph/twp/files/Triple\%20Win\%20 Philipinen.pdf?fbclid=IwAR268JmtSJ-b8R1Os-b46exymc9SQjMvtjVDd_ XrYeCvagJGbjXMTSzQ-j8 (accessed 9 April 2019).

Primono, J. 2000. Nursing around the world: Japan preparing for the century of the elderly. Online Journal of Issues in Nursing 5 (2), http://www.nursingworld.org/ MainMenuCategories/ANAMarketplace/ANAPeriodicals/OJIN/TableofContents/ Volume52000/No2May00/JapanElderlyCentury.aspx (accessed 9 April 2019).

Raghuram, P. and Kofman, E. 2004. Out of Asia: Skilling, re-skilling and deskilling of female migrants. Women's Studies International Forum 27 (2): 95-100, https://doi. org/10.1016/j.wsif.2004.06.001.

Rey, A. 2018. More Filipino nurses seek jobs in U.S. in 2017. Rappler, 19 May. https:// www.rappler.com/nation/202890-more-filipino-nurses-jobs-usa-2017 (accessed 7 November 2018).

Rodwell, C. M. 1996. An analysis of the concept of empowerment. Journal of Advanced Nursing 23 (2): 305-313, https://doi.org/10.1111/j.1365-2648.1996.tb02672.x.

Siar, S. 2013. From highly skilled to low skilled: Revisiting the deskilling of migrant labor. Discussion paper series, Philippine Institute for Developmental Studies, http://hdl. handle.net/10419/126949 (accessed 10 January 2018). 
Sharkey, A. and Sharkey, N. 2012. Granny and the robots: Ethical issues in robot care for the elderly. Ethics and Information Technology 14 (1): 27-40, https://doi.org/10.1007/ s10676-010-9234-6.

Spence Laschinger, H., Finegan, J. and Shamian, J. 2002. The impact of workplace empowerment, organizational trust on staff nurses' work satisfaction and organizational commitment. Advances in Health Care Management 3: 59-85, https://doi.org/10.1016/S1474-8231(02)03006-9.

Spence Laschinger, H. et al. 2009. Workplace empowerment, incivility and burnout: Impact on staff recruitment and retention outcomes. Journal of Nursing Management 17 (3): 302-311, https://doi.org/10.1111/j.1365-2834.2009.00999.x.

Suzuki, W. 2018. Abe bets big on adding foreign workers. Nikkei Asian Review, https:// asia.nikkei.com/Spotlight/Japan-Immigration/Abe-bets-big-on-adding-foreignworkers (accessed 3 November 2018).

Takahashi, K. 2018. Japan's immigration policy and the EPA between the Philippines and Japan. Academic paper, Yamagata University Faculty of Humanities, 3, 161-170, https://www-hs.yamagata-u.ac.jp/wp-content/uploads/2018/03/10TAKAHASHI. pdf (accessed 9 April 2019).

Triple Win Bewerber Information. 2013. Placement of qualified nurses from the Philippines to Germany. http://www.poea.gov.ph/TWP/files/Triple\%20Win\%20Philipinen.pdf (accessed 25 June 2019).

Tsujimura, M. et al. 2016. Cultural characteristics of nursing practice in Japan. International Journal of Nursing Practice 22 (1): 56-64, https://doi.org/10.1111/ijn.12440.

Venzon, L. and Venzon, R. 2005. Professional nursing in the Philippines, 10th ed. Quezon City: C \& E Publishing.

Vogt, G. 2018. Population aging and international health-caregiver migration to Japan. Cham, Switzerland: Springer.

Wallerstein, N. 1992. Powerlessness, empowerment, and health: Implications for health promotion programs. American Journal of Health Promotion 6 (3): 197-205, https://doi.org/10.4278/0890-1171-6.3.197. 